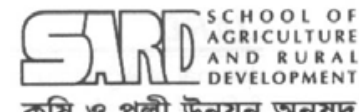

কৃষि ও পল্লী উন্ময়ন অনুষদ
Available online at http:/ / www.banglajol.info/index.php/jard
J ARD

Journal of Agriculture \& Rural Development

\title{
Attitude of Coastal Rural Youth towards Some Selected Modern Agricultural Technologies
}

\author{
M. E. UDDIN ${ }^{* 1}$, M. U. RASHID ${ }^{2}$ \& M. G. R. AKANDA ${ }^{3}$ \\ ${ }^{1,2 \& 3}$ Dept. of Agricultural Extension and Rural Development, Patuakhali Science and Technology \\ University, Dumki, Patuakhali, Bangladesh
}

\begin{abstract}
The main objective of the study was to determine the attitude of the coastal rural youth towards some selected modern agricultural technologies. Data were collected from randomly selected 91 coastal rural youth of Patuakhali district using a pre-tested structured interview schedule during 15 May to 31 May 2007. Attitude of the coastal rural youth towards some selected modern agricultural technologies was the dependent variable of the study. Ten selected individual characteristics of the coastal rural youth namely age, education, family size, family farm size, family annual income, aspiration, innovativeness, extension media contact, agricultural knowledge and time spent in agricultural activities were considered as the independent variables of the study. Highest proportion (71.43\%) of the coastal rural youth had moderately favorable attitude while $10.99 \%$ and $17.58 \%$ youth showed unfavorable and favorable attitude, respectively, towards selected modern agricultural technologies. Education, innovativeness and agricultural knowledge of the coastal rural youth had positive and significant relationship with their attitude towards selected modern agricultural technologies. The other variables did not show any significant relationship.
\end{abstract}

Key words: Attitude, rural youth, agricultural technologies.

\section{INTRODUCTION}

Youths are the power. The overall development of a country depends on their regimented, active and skilled youth power. About one third of the total population of Bangladesh is youth, which is near about four and quarter crore (DYD, 2004). By their dominant figure and energy young people can make an immense contribution in nation building. They would be able to play a foremost part in building global food security and development. Unfortunately many of the youth will not get the chance to fulfill that potential because of the unfavorable attitude formation. Lack of education, training and organizational program they turn into unproductive (Ali and Anwar, 2000).

About one third area of Bangladesh is covered by coastal area. The total population in the coastal zone is 36.83 million of which 10.8 million is youth (WARPO, 2006). Therefore, overall development of the country immensely depends upon the development of this region. Rural youths are closely involved in agriculture. Most often school dropout, unskilled and unemployed coastal youth face serious difficulties in maintaining their daily life. Due to lack of adequate literacy, ample

* Corresponding author: Lecturer, Dept. of Agricultural Extension and Rural Development, PSTU, Dumki, Patuakhali

(C) 2008 School of Agriculture and Rural Development, Bangladesh Open University, All rights reserved. 


\section{E. Uddin et al.}

knowledge on agricultural information and technology they cannot achieve the desired production of crops. Many of them do not have enough skills in handling the modern agricultural technologies.

Bangladesh is an agrarian country and the situations are favorable to make the coastal rural youth self-empowered through adopting modern agricultural technologies. An educated youth can also support his family giving necessary suggestion in practicing modern agricultural technologies. Youth are the future of the nation. Their thinking and attitude is projected in their action. So, it is essential to know the attitude of the coastal rural youth before transferring agricultural technologies in the coastal region. Therefore, the present study was undertaken with the following specific objectives.

1. To determine the attitude of the coastal rural youth towards some selected agricultural technologies. The selected technologies are-HYV rice cultivation, vegetable cultivation and agroforestry practice.

2. To describe some selected characteristics of the coastal rural youth. The characteristics areage, education, family size, family farm size, family annual income, aspiration, innovativeness, extension media contact, agricultural knowledge and time spent in agricultural activities.

3. To explore the relationship of the selected characteristics of the coastal rural youth with their attitude towards some selected agricultural technologies.

\section{MATERIALS AND METHODS}

The population of the study was all the rural youth including both male and female youth of the three-selected village namely, Santosdi, Boga Bandar and Chargarabdi under Patuakhali district. A list of 450 youth was prepared in advanced as the population of the study. From the population $20 \%$ respondent were selected randomly. Hence, the sample size was ninety-one (91). Data were collected by the researcher themselves. A structured interview schedule was used for collection of data during 15 May to 31 May 2007.

\section{Variables of the study}

Attitude of the coastal rural youth towards some selected modern agricultural technologies was the dependent variable of the study. The researcher selected three modern agricultural technologies viz. cultivation of HYV rice, cultivation of vegetables and adopting agroforestry system as a sustainable land use system for the coastal area. Besides, ten selected individual characteristics of the coastal rural youth namely age, education, family size, family farm size, family annual income, aspiration, innovativeness, extension media contact, agricultural knowledge and time spent in agricultural activities were considered as the independent variables of the study.

\section{Measurement of the dependent variable}

Attitude of the coastal rural youth towards some selected modern agricultural technologies was ascertained through a 5-point-Likert type scale having 4-statements for each technology. Hence, agreement on twelve ( $3 \times 4=12)$ statements were ascertained as 'strongly agree', 'agree', 'undecided', 'disagree' and 'strongly disagree' with corresponding score of 4, 3, 2, 1 and 0 . Thus, for a respondent the attitude score could rang from 0 to 48 where 0 indicates most unfavorable attitude and 48 indicates most favorable attitude.

\section{RESULTS AND DISCUSSION}

\section{Some basic features of individual characteristics}

The basic statistical values of individual characteristics are shown in Table 1 which is self-explanatory 
Table 1. Descriptive statistics of independent variables

\begin{tabular}{|c|c|c|c|c|c|c|c|c|}
\hline \multirow{2}{*}{$\begin{array}{c}\text { Selected } \\
\text { characteristics }\end{array}$} & \multirow[t]{2}{*}{ Categories } & \multicolumn{2}{|c|}{ Respondent } & \multirow{2}{*}{$\begin{array}{l}\text { Scoring } \\
\text { method }\end{array}$} & \multicolumn{2}{|c|}{ Range } & \multirow[t]{2}{*}{ Mean } & \multirow[t]{2}{*}{ SD } \\
\hline & & No. & $\%$ & & Min & Max & & \\
\hline \multirow[t]{3}{*}{ Age } & Younger youth (15-22) & 22 & 24.17 & & & & & \\
\hline & Youth (23-30) & 25 & 27.47 & years & 15 & 35 & 28.63 & 6.25 \\
\hline & Older youth (29-35) & 44 & 48.35 & & & & & \\
\hline \multirow[t]{5}{*}{ Education } & Illiterate $(0)$ & 5 & 5.49 & & & & & \\
\hline & Semi-literate $(0.5)$ & 5 & 5.49 & Years of & & & & \\
\hline & Primary (1-5) & 22 & 24.17 & schooling & 0 & 14 & 7.20 & 3.66 \\
\hline & Secondary (6-10) & 49 & 53.84 & & & & & \\
\hline & Higher secondary \& above $(>10)$ & 10 & 10.98 & & & & & \\
\hline \multirow[t]{3}{*}{ Family size } & Small family (2-4) & 22 & 24.17 & & & & & \\
\hline & Medium family (5-8) & 53 & 58.24 & Number & 3 & 10 & 6.48 & 2.73 \\
\hline & Large family (9-20) & 16 & 17.58 & & & & & \\
\hline Family farm & Marginal (up to 0.20 ) & 6 & 6.59 & & & & & \\
\hline \multirow[t]{3}{*}{ size } & Small farmer (0.21-1.0) & 40 & 43.95 & Hectare & 0.06 & 16.76 & 1.51 & 2.00 \\
\hline & Medium farm (1.1-3.0) & 34 & 37.36 & & & & & \\
\hline & Large farm (above 3.0) & 11 & 12.08 & & & & & \\
\hline Family annual & Low income (4-50) & 33 & 36.26 & & & & & \\
\hline \multirow[t]{2}{*}{ income } & Medium (51-120) & 47 & 51.64 & Rated score & 4.00 & 507 & 77.41 & 75.16 \\
\hline & High income $(>120)$ & 14 & 15.38 & & & & & \\
\hline \multirow[t]{3}{*}{ Aspiration } & Low (4-12) & 18 & 19.78 & & & & & \\
\hline & Medium (13-18) & 52 & 57.14 & Rated score & 4 & 30 & 15.64 & 4.04 \\
\hline & High (19-30) & 21 & 23.07 & & & & & \\
\hline \multirow[t]{3}{*}{ Innovativeness } & Less innovative (0-9) & 19 & 20.87 & & & & & \\
\hline & Moderate $(10-20)$ & 52 & 57.14 & Rated score & 0 & 26 & 14.95 & 6.34 \\
\hline & Highly innovative (21-28) & 20 & 21.97 & & & & & \\
\hline Extension & Low $(0-10)$ & 21 & 23.07 & & & & & \\
\hline \multirow[t]{2}{*}{ media contact } & Medium (11-18) & 49 & 53.84 & Rated score & 0 & 32 & 15.01 & 6.55 \\
\hline & High (19-42) & 21 & 23.07 & & & & & \\
\hline Agricultural & Low $(0-20)$ & 14 & 15.38 & & & & & \\
\hline \multirow[t]{2}{*}{ knowledge } & Medium (21-27) & 53 & 58.24 & Rated score & 14 & 30 & 24.62 & 3.84 \\
\hline & High (28-30) & 24 & 26.37 & & & & & \\
\hline Time spent in & Less $(0-23)$ & 19 & 20.87 & & & & & \\
\hline agricultural & Moderate (24-90) & 56 & 61.53 & Rated score & 0 & 182 & 59.24 & 37.43 \\
\hline activities & More (91-182) & 16 & 17.58 & & & & & \\
\hline
\end{tabular}

\section{Attitude of the coastal rural youth towards selected agricultural technologies}

Attitude of the coastal rural youth towards some selected agricultural technologies was categorized into thee as 'unfavorable attitude', 'moderately favorable attitude' and 'favorable attitude' according to their mean attitude score (30.33) and standard deviation (8.0). Data in the Table 2 indicate that highest proportion (71.43\%) of the coastal rural youth had moderately favorable attitude while $10.99 \%$ and $17.58 \%$ youth showed unfavorable and favorable attitude, respectively, towards selected modern agricultural technologies. In fact most of the coastal rural youth had an orientation towards Dhaka and other big cities, which was reflected in their attitude formation.

Table 2. Distribution of coastal rural youth according to their attitude towards some selected agricultural technologies

\begin{tabular}{|c|c|c|c|c|}
\hline \multirow[t]{2}{*}{ Categories of attitude } & \multicolumn{4}{|c|}{ Coastal rural youth $(\mathrm{N}=91)$} \\
\hline & Number & Percent & Mean & SD \\
\hline Unfavorable $(<22.33)$ & 10 & 10.99 & & \\
\hline Moderately favorable (22.33-38.33) & 65 & 71.43 & 30.33 & 8.00 \\
\hline Favorable (>38.33) & 16 & 17.58 & & \\
\hline Total & 91 & 100 & & \\
\hline
\end{tabular}


Relationship of selected individual characteristics of the coastal rural youth and their attitude towards some selected agricultural technologies:

The Table 3 shows that education, innovativeness and agricultural knowledge of the coastal rural youth had positive and significant relationship with their attitude towards selected modern agricultural technologies. On the other hand age, family size, family farm size, family annual income, aspiration, extension media contact and time spent in agricultural activities had no significant relationship with their attitude. Haque et al. (2003) and Chowdhury et al. (2003) also found more or less similar result in their study.

Education, innovativeness and agricultural knowledge are very much interrelated and influenced by each other. Man with higher level of education have broad mental faculty. An educated youth has more exposure to knowledge and information source regarding to new modern technologies. On the other hand educated youth has rational thinking and more external orientation, which also favors their attitude formation towards modern agricultural technologies.

Coastal area is very much vulnerable to natural disaster like cyclone, tidal flood, river bank erosion and salinity problems which very often caused damage to agricultural crops, livestock and also the lives and other properties of the dweller. Hence, coastal rural youth are very much realistic in behavior and they think that they have to be educated and a government job is better than other professions. Probably these were the reasons why other variables showed insignificant relationship with the attitude of the coastal rural youth towards the selected agricultural technologies.

Table 3. Relationship of selected individual characteristics of the coastal rural youth and their attitude towards some selected agricultural technologies

\begin{tabular}{lc}
\hline Selected individual characteristics & Correlation coefficient $(r)$ \\
\hline Age & $-.086^{\mathrm{NS}}$ \\
Education & $0.274^{* \star}$ \\
Family size & $-.029^{\mathrm{NS}}$ \\
Family farm size & $0.137^{\mathrm{NS}}$ \\
Family annual income & $0.122^{\mathrm{NS}}$ \\
Aspiration & $0.138^{\mathrm{NS}}$ \\
Innovativeness & $0.286^{* \star}$ \\
Extension media contact & $0.052^{\mathrm{NS}}$ \\
Agricultural knowledge & $0.345^{* *}$ \\
Time spent in agricultural activities & $0.173^{\mathrm{NS}}$ \\
\hline
\end{tabular}

* = Significant at 1 percent level

NS = Non-significant

\section{Features of the selected technologies according to attitude response:}

The Table 4 shows that the maximum range of attitude score was 16 in all the three case of the selected technologies. But the minimum score was observed 0 in Agroforestry and 1 in HYV rice cultivation and 8 in vegetable cultivation. This feature indicates that some of the coastal rural youth has no knowledge on agroforestry practice as a sustainable land use system. On the other hand the mean attitude score was also highest in vegetable technology, which is clearly visible in bar graph (Figure 1). The fact was that vegetable is demandable and production of vegetable is profitable in coastal area.

Table 4. Features of the three selected agricultural technologies according to the mean attitude score of the respondent

\begin{tabular}{l|c|c|c}
\hline Name of the technologies & Range of attitude score & Mean & SD \\
\hline HYV rice cultivation & $1-16$ & 8.91 & 3.65 \\
Vegetables cultivation & $8-16$ & 13.06 & 2.22 \\
Agroforestry practice & $0-16$ & 8.73 & 3.60 \\
\hline
\end{tabular}


Attitude of coastal rural youth towards some selected modern agricultural technologies

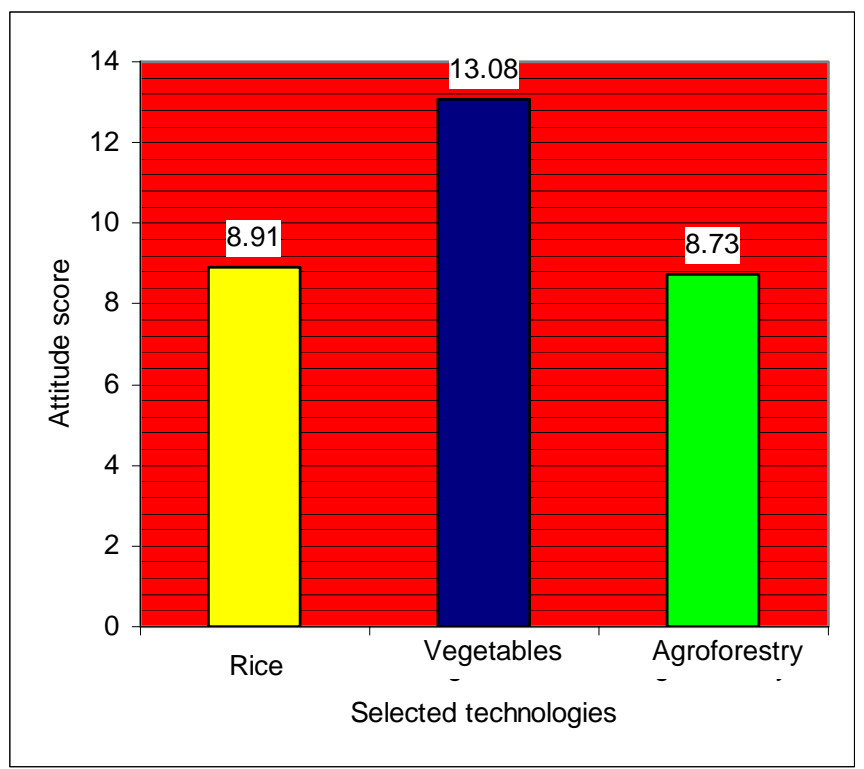

Figure 1. Bar graph showing the attitude performance of the three technologies

\section{CONCLUSION}

From the above discussion it was explored that most of the coastal youth possessed moderately favorable attitude towards the selected agricultural technologies while others had less favorable and highly favorable attitude towards them in almost equal proportion. Among the selected variables education, innovativeness and agricultural knowledge had positive significant relationship with attitude change while other variables such as age, family size, family farm size, aspiration, extension media contact and time spent in agricultural activities had non-significant relationship with attitude change.

\section{RECOMMENDATIONS}

1. As education was a significant variable for change of attitude so different GOs and NGOs should come forward with different educational program like mass education, adult literacy, vocational education etc to make coastal rural youth educated.

2. As innovation was found to be significant influence on the attitude change so different communication media should come forward with economically viable agricultural technology to increase innovations among coastal people. Simultaneously communication infrastructure should be developed as GOs and NGOs can come forward and work with coastal people to initiate positive motivation.

3. Agricultural knowledge was another important significant variable that could be ameliorated by launching different training programs, establishing youth club, different demonstration, farmers' field school etc in this region for developing agricultural knowledge among coastal rural youth.

4. In coastal area lands are vulnerable to erosion and are flooded by tidal water now and then. Agroforestry practice can be an effective measure to protect this area from natural hazards like cyclone, tornadoes, landslides, river bank erosion and soil salinity. Hence, concerned authorities should strengthen their campaign on agroforestry practices in this region. 


\section{E. Uddin et al.}

\section{LITERATURE CITED}

Ali, M. A. and Anwar, A. B. M. 2000. Anticipated problem confrontation of the unemployed rural youth for undertaking selected agricultural income generating activities for the employment. Bang J Ext Ed 11\&12(1\&2), 61-68.

Chowdhury, A. H. 2003. Farmers attitude towards crop diversification. Unpublished [MS Thesis], Department of Agricultural Extension Education, Bangladesh Agricultural University, Mymensingh.

DYD. 2004. "Proshikhan Karjakram". Deparment of Youth Development, Ministry of youth and Sports, Government of the Peoples Republic of Bangladesh, Dhaka.

Haque, M. E., Rahman, M. H and Fafouque, M. G. 2003. Farmers attitude towards extension activities of the department of agricultural extension. Bang J Ext Ed 15(1\&2), 83-88.

WARPO. 2006. "State of the Coast". Ministry of Water Resources, Government of the Peoples Republic of Bangladesh, Dhaka. 